\title{
Use of Quickfix for tape fixation of chest tubes: a multi-center doctor-nurse questionnaire survey and fixing strength comparison study
}

\author{
Takahiro Homma ${ }^{1,2}$, Toshihiro Ojima ${ }^{1,2}$, Yoshifumi Shimada ${ }^{1}$, Yushi Akemoto ${ }^{1}$, Naoki Yoshimura ${ }^{1}$ \\ ${ }^{1}$ Department of General Thoracic and Cardiovascular Surgery, Graduate School of Medicine and Pharmaceutical Sciences, University of Toyama, \\ Toyama, Japan; ${ }^{2}$ Division of Thoracic Surgery, Joetsu General Hospital, Niigata, Japan \\ Contributions: (I) Conception and design: T Homma; (II) Administrative support: T Homma, N Yoshimura; (III) Provision of study materials or \\ patients: All authors; (IV) Collection and assembly of data: All authors; (V) Data analysis and interpretation: T Homma; (VI) Manuscript writing: All \\ authors; (VII) Final approval of manuscript: All authors. \\ Correspondence to: Takahiro Homma. Department of General Thoracic and Cardiovascular Surgery, Graduate School of Medicine and Pharmaceutical \\ Sciences, University of Toyama, 2630 Sugitani, Toyama, Toyama, 930-0194, Japan. Email: hommat@med.u-toyama.ac.jp.
}

\begin{abstract}
Background: Several tape fixations for chest tube were proposed, although none have a clear scientific basis. We performed a multicenter survey study to investigate the fixation of chest tubes using an available adhesive tape. We evaluated the strength of tape fixation and the effect of the skin coating material used on the fixation strength.

Methods: A multi-center questionnaire survey was administered in hospitals with a thoracic surgery division. The net promoter score (NPS) was used to measure the medical staff's satisfaction with an adhesive tape fixation. Fixing strength was calculated as follows: a chest tube was fixed using each taping method to a polyethylene plate and was pulled out in the long axis direction. While pulling out, the maximum resistance force $[$ Newton $(\mathrm{N})$ ] and total resistance force [Joule (J)] were measured to calculate the fixing strength.

Results: The doctors' NPS showed no significant difference between handmade tape fixation and Quickfix $\{7$ [5-8] vs. 10 [5-10] points, $\mathrm{P}=0.34\}$. The nurses' NPS showed no significant difference between handmade tape fixation and Quickfix $\{5[5-8]$ vs. 5 [5-7] points, $\mathrm{P}=0.72\}$. The average maximum resistance force was the highest for Quickfix $(1.36 \mathrm{~J}, 65.4 \mathrm{~N})$ and a type of handmade fixation (three sheets stuck with foundation tape plus Y-shape slit plus $\Omega$-shape tape; $1.61 \mathrm{~J}$ and $54.0 \mathrm{~N}$ ). The fixation strength of Quickfix did not decrease with a skin coating agent (from 1.24 to $1.11 \mathrm{~J}$ and 63.0 to $66.6 \mathrm{~N}$ ), although that of a handmade tape fixation decreased (from 1.49 to $0.90 \mathrm{~J}, 52.6$ to $38.1 \mathrm{~N}$ ).

Conclusions: Quickfix provided secure fixation, regardless of the tube size or skin coating. Quickfix may be the best for standardized fixation because it is not only a stronger agent but is safe, simple, inexpensive, reliable, and can be used successfully by anyone.
\end{abstract}

Keywords: Chest tube; drainage; management; thoracic surgery; nursing care; intensive care

Submitted Oct 27, 2019. Accepted for publication Dec 26, 2019.

doi: $10.21037 /$ jtd.2019.12.132

View this article at: http://dx.doi.org/10.21037/jtd.2019.12.132

\section{Introduction}

A drainage tube has mainly two roles. One is to provide information about active bleeding and leaks from the anastomosis or the resection stump; the other role is to discharge fluid or air in the body $(1,2)$. Unintentional drainage tube removal is a big concern in safety management. In Japan, a chest tube is generally fixed with ligation and handmade adhesive tape. In particular, various fixation methods with handmade adhesive tape are used (Figure $1 A, B, C, D, E$ ). 

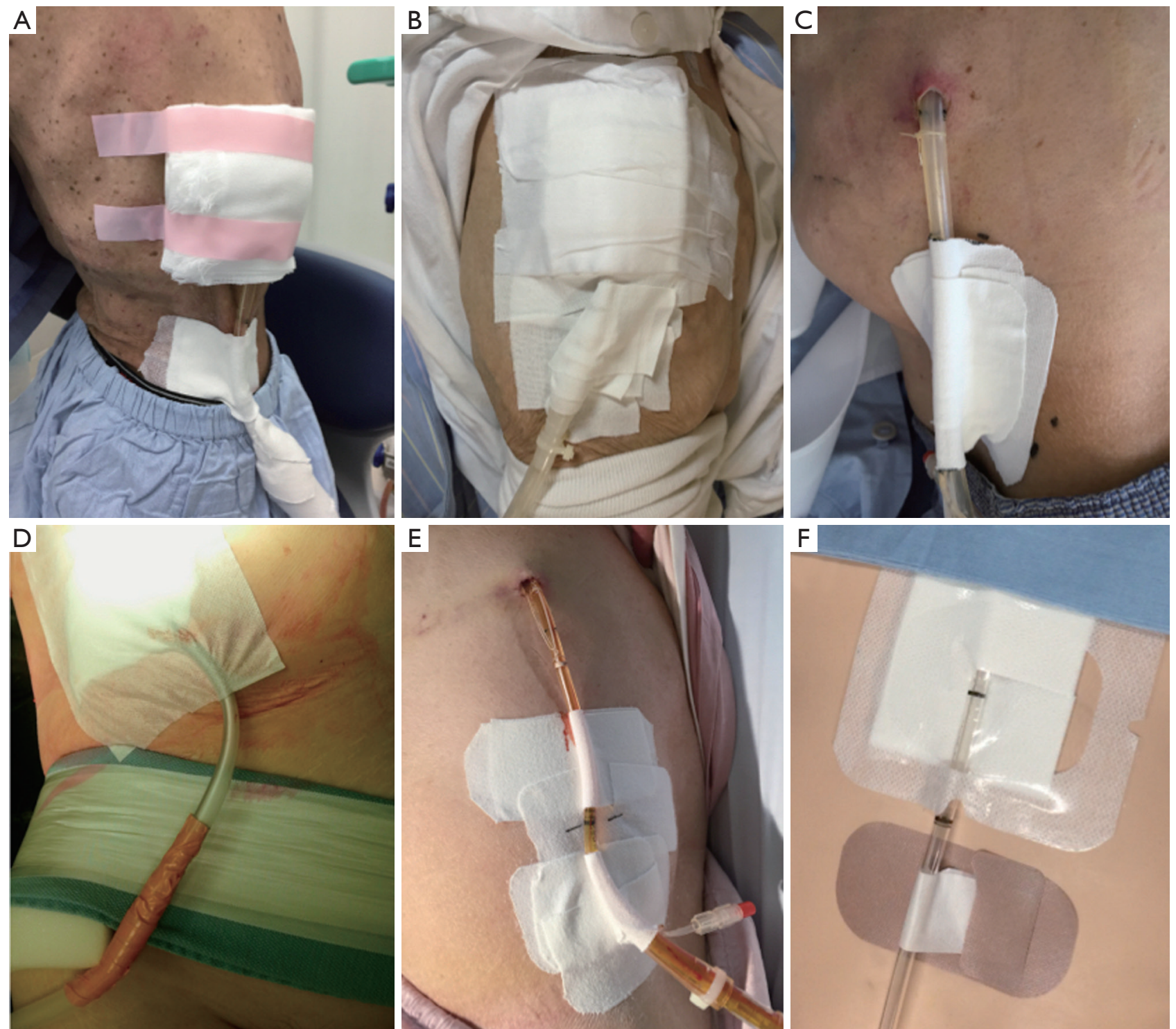

Figure 1 Photographs showing various tape fixations for chest tube. (A,B,C,D,E) Various handmade tape fixations in some hospitals. (F) Tape fixation using Quickfix.

In contrast, catheter or drain fixation products, such as Quickfix (ALCARE, Tokyo, Japan; Figures 1F,2), StatLock (Becton, Dickinson and Company, Franklin Lakes, NJ), SecurAcath (Interrad Medical), Cath Grip (BioDerm), and Vertical tube attachment device and Horizontal tube attachment device (Hollister), have recently been developed. Among them, Quickfix is the most widely accepted product in Japan. Quickfix is applied with round-cut-shape and $\Omega$-shape tape fixation techniques (Figure 3); some size variations of the drain size have been noted (Figure 2).
Anyone can paste it within approximately 30 seconds, and it is inexpensive, being priced at approximately 40-60 yen.

To date, there are some reports on the fixation of central venous catheter and tracheal tubes (3-7), but there are few reports on chest tube fixation. Unintentional chest tube removal can lead to fatal complications. We are not aware of the available methods and of the best chest tube fixation method. Adhesive tape fixation has been used in the clinic without a systematic scientific basis. Moreover, if increased adhesiveness of the tape is desired, the patient may experience 


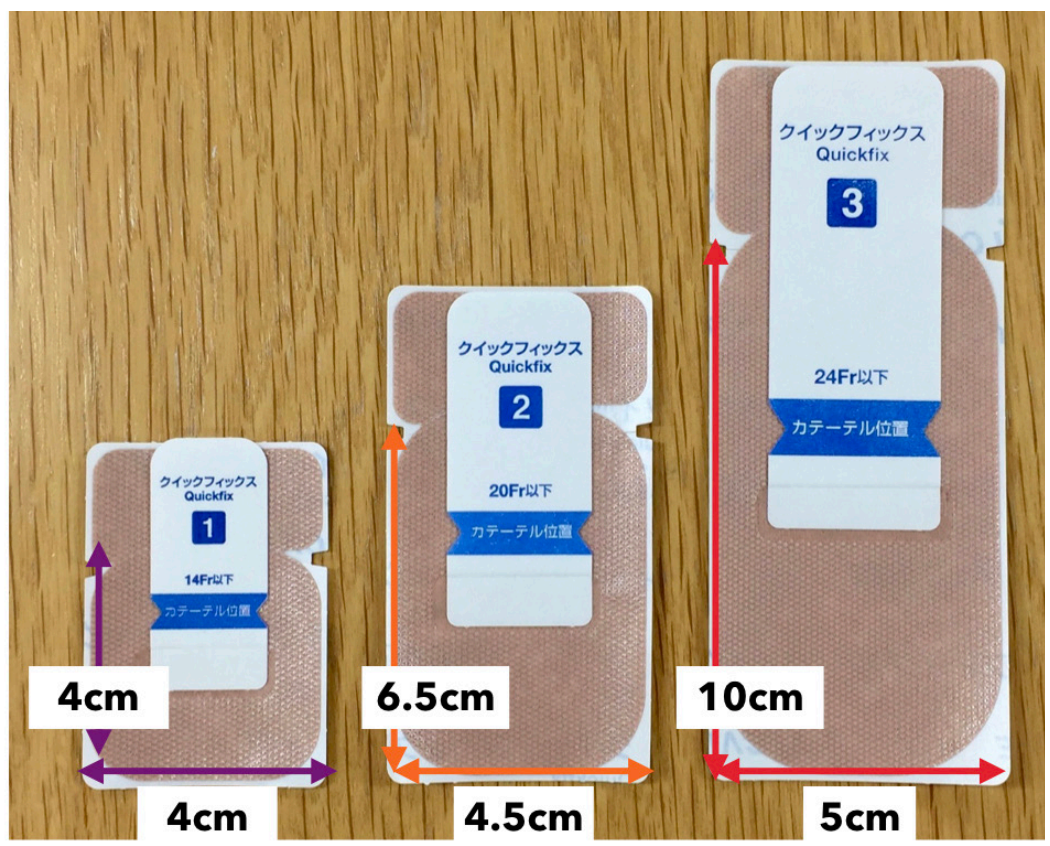

Figure 2 Quickfix had three sizes depending on the tube size.

A

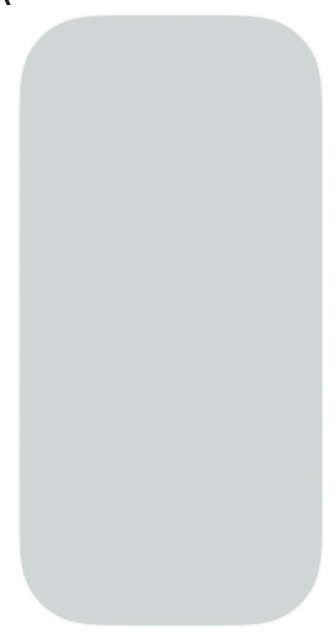

B

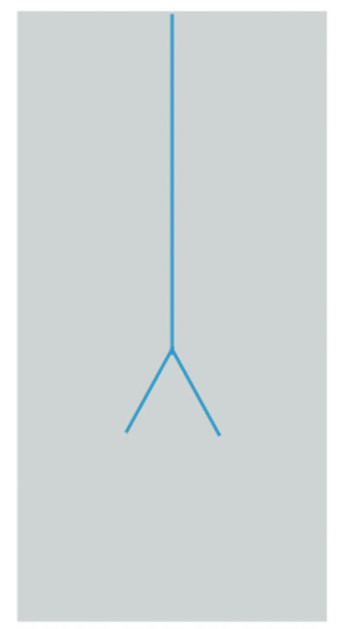

C
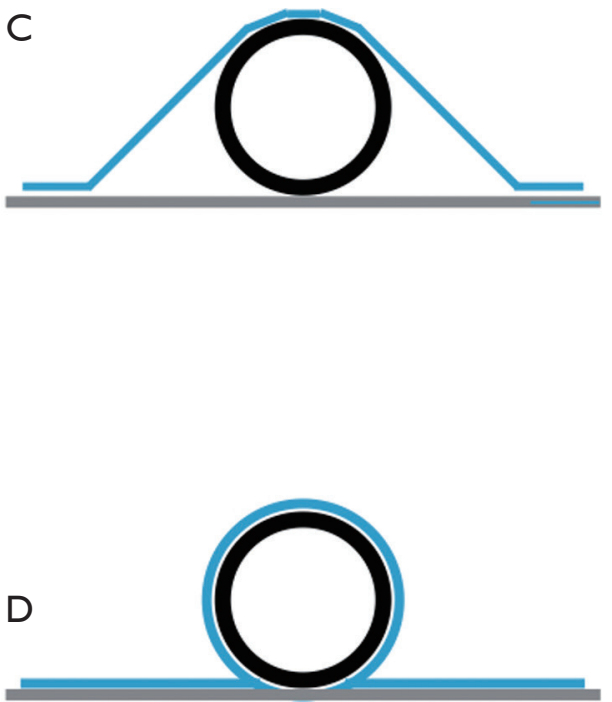

Figure 3 Handmade tape fixation techniques for maximizing adhesive strength and minimizing skin trouble. (A) Tape with corners cut in the round shape (round-cut). (B) Tape with slit in the Y-shape (Y-shape slit). (C) Tape stuck on the tube. The blue line shows the tape and the black circle shows the tube. (D) Tape stuck close around the tube ( $\Omega$-shape tape).

skin troubles (Figure 4). For the prevention of skin troubles, skin coating materials, such as Remois Coat (ALCARE, Tokyo, Japan) or Secura (Smith and Nephew, Watford, UK), are frequently used. We are concerned about the effect of the skin coating materials used on strength of tape fixation. We, therefore, performed this multicenter questionnaire study and aimed to investigate how to fix a chest tube using an available adhesive tape. We also assessed the fixation strength 


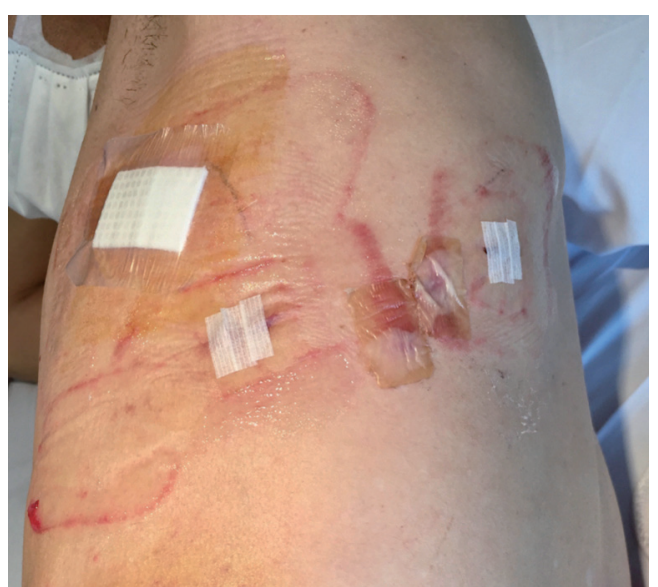

Figure 4 Skin troubles cause by tape adhesiveness.

in the presence and absence of a skin coating material.

\section{Methods}

\section{Study design and participants}

This study was a multi-center descriptive and questionnairebased survey conducted in hospitals with a division of thoracic surgery in the four prefectures in Japan, namely, Niigata, Toyama, Ishikawa, and Fukui. The fixing strength of the tape was investigated. The study was approved by the Ethics Committee of the Joetsu General Hospital (J181).

\section{Variables and assessments}

This descriptive questionnaire survey consisted of 12 questions and included the following variables: hospital, division, work experiences years, questions like, "How do you fix a chest tube? (handmade/products/no tape fixation)", "To whom did you teach the fixation? (doctor/colleague/ textbook/workshop/others)", "Do you have any standard rule for the fixation? (ward/team/attending doctor/attending nurse/no rule)", "How many sheets of tapes do you use in a handmade tape fixation?", "How do you fix with handmade tape?", "Do you cut corners like round? (roundcut)" (Figure 3A), "Do you cut a Y-shape (Y-shape slit)" (Figure $3 B$ ), and "Do you stick the tape closely around chest tube forming to $\Omega$-shape ( $\Omega$-shape tape)?” (Figure $3 C, D)$, the net promotor score (NPS), and the question, "How likely is it that you would recommend your tape fixation method to a colleague?".

\section{NPS}

The NPS was used to measure medical staff satisfaction with adhesive tapes, such as Quickfix, to fix the chest tube. This metric is calculated based on responses to a single question: "How likely is it that you would recommend your tape fixation method of chest tube to a colleague?" The answers were ranked on a numeric scale between 0 (absolutely unlikely recommendation) and 10 (highest likelihood of recommendation) points $(8,9)$.

\section{Participants}

Thoracic surgeons in the four prefectures provided consent and were accordingly enrolled in this survey, with an understanding that they would provide data about themselves and that we would collect data over time. In the hospitals using fixation products, nurses working in units that managed chest tubes, namely, nurses working in the intensive care unit, thoracic surgery ward, respiratory ward, emergency care unit, and operation room, were enrolled.

\section{Tape fixing strength comparison test}

Fixing strength was calculated by the following process: a chest tube was fixed by each tape method to a polyethylene plate. Tape fixation methods were performed to mimic the methods identified in the descriptive questionnaire survey. The recommended size is defined by the drain size (Figure 2). Handmade tape fixation used SilkyTex 5 (ALCARE, Tokyo, Japan), which was cut $5 \mathrm{~cm} \times 10 \mathrm{~cm}$. Chest tubes used included Argyle trocar catheters of 16, 20, and $24 \mathrm{Fr}$ (Cardinal Health, Dublin, $\mathrm{OH}$ ).

After 20 minutes of tape fixation, a tube was pulled out in the long axis direction at a speed of $1,000 \mathrm{~mm} / \mathrm{min}$ by Autograph AGS-X (Shimadzu Corporation, Kyoto, Japan; Figure $5 A, B)$. During pulling it out, the maximum resistance force [Newton $(\mathrm{N})]$ and total resistance force [Joule (J)] were measured as parameters of fixing strength. The measurements for each tape fixation method were performed three times, and the average values were compared.

In the study, the skin coating agent, Remois Coat (ALCARE, Tokyo, Japan), was used. Remois Coat was sprayed from a distance of $10 \mathrm{~cm}$ from the polyethylene plate, and tape fixation was performed after 30 seconds; the tape fixation strength was then measured, as described above. 

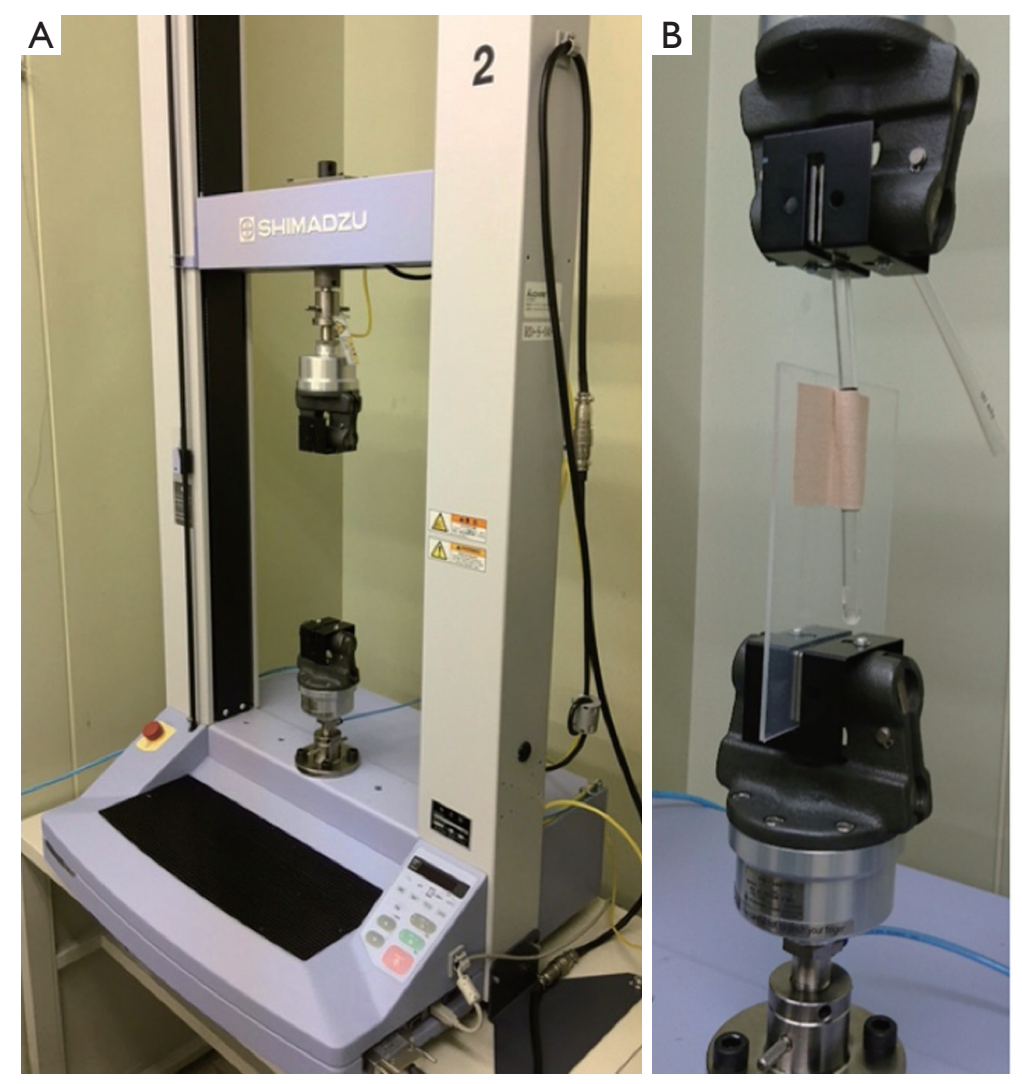

Figure 5 Tape fixing strength test. (A) Autograph AGS-X (Shimadzu Corporation, Kyoto, Japan). (B) The tube pulling out in the long axis direction at a speed of $1,000 \mathrm{~mm} / \mathrm{min}$. During pulling it out, the maximum resistance force (Newton) and total resistance force (Joule) were measured as fixing strength by Autograph AGS-X.

\section{Statistical analysis}

For the univariate analysis, differences between groups were evaluated using a non-parametric Wilcoxon rank-sum test, and either the $\chi^{2}$ test or Fisher's exact test for categorical variables, when necessary. Spearman rank correlation analysis was used to analyze the correlation between working experience in years and the tape fixing method. All statistical analyses were performed with JMP software version 12.0 (SAS Institute, Inc., Cary, NC, USA). For all the analyses, statistical significance was defined as $\mathrm{P}<0.05$.

\section{Results}

Twenty-eight thoracic surgeons from 14 hospitals participated in the survey (Table 1). The median of years of working experience was 14 [1-32] years. Twenty-four doctors $(85.7 \%)$ in 12 hospitals performed handmade tape fixation and four doctors (14.3\%) in two hospitals fixed chest tubes using Quickfix, as one of the fixation products. All four doctors using Quickfix used to perform handmade tape fixation.

All doctors learned the handmade tape fixation technique from doctor's colleagues, and none of them learned the technique from others other colleague, textbook, workshop. The fixation method was standardized in the ward in 10 hospitals $(71.4 \%)$, while the method depended on the attending doctor in two hospitals (14.3\%), the attending nurse or nurses in one hospital $(7.1 \%)$, and in some cases, the fixation method varied according to the patients. With respect to the number of tape sheets used for handmade tape fixation, we found that eight doctors $(28.6 \%)$ used one sheet, 11 doctors (39.3\%) used two sheets, six doctors (21.4\%) used three sheets, and two doctors (7.1\%) used four sheets. Round-cut Y-shape slit was used by four doctors (14.3\%), and the $\Omega$-shaped tape was used by 24 doctors (85.7\%).

The NPS for the doctors showed no significant 
Table 1 Descriptive questionnaire survey of tape fixation for chest tube

\begin{tabular}{|c|c|c|}
\hline Variable & Doctor $(n=28)$ & Nurse $(n=110)$ \\
\hline $\begin{array}{l}\text { Working experiences } \\
\text { (median, years) }\end{array}$ & $14[1-32]$ & $6[0.5-41]$ \\
\hline \multicolumn{3}{|l|}{ Type } \\
\hline Handmade tape fixation & $24(85.7)$ & - \\
\hline Quickfix & $4(14.3)$ & - \\
\hline \multicolumn{3}{|l|}{ How to learn } \\
\hline Colleague & $14(100.0)$ & $72(65.5)$ \\
\hline Doctor & - & $22(20.0)$ \\
\hline Textbook & $0(0)$ & $9(8.2)$ \\
\hline Workshop & $0(0)$ & $7(6.4)$ \\
\hline \multicolumn{3}{|l|}{ Rule } \\
\hline Ward & $20(71.4)$ & $20(18.2)$ \\
\hline Team & $0(0)$ & $35(31.8)$ \\
\hline Attending doctor & $4(14.3)$ & $12(10.9)$ \\
\hline Attending nurse & $2(7.1)$ & $26(23.6)$ \\
\hline No rule & $2(7.1)$ & $17(15.5)$ \\
\hline \multicolumn{3}{|l|}{ How many sheets of tapes } \\
\hline 0 & $1(3.6)$ & $0(0)$ \\
\hline 1 & $8(28.6)$ & $0(0)$ \\
\hline 2 & $11(39.3)$ & $64(58.2)$ \\
\hline 3 & $6(21.4)$ & $38(34.5)$ \\
\hline 4 & $2(7.1)$ & $8(7.3)$ \\
\hline \multicolumn{3}{|l|}{$\begin{array}{l}\text { Techniques of handmade } \\
\text { tape fixation }\end{array}$} \\
\hline Round-cut & $4(14.3)$ & $108(98.2)$ \\
\hline Y-shape slit & $4(14.3)$ & $93(84.5)$ \\
\hline$\Omega$-shape stick & $24(85.7)$ & $110(100.0)$ \\
\hline
\end{tabular}

difference between handmade tape fixation and Quickfix $\{7$ [5-8] vs. 10 [5-10] points, $\mathrm{P}=0.34$; Table 2\}.

In the two hospitals that adopted Quickfix, the duration of use was three years and nine months at one hospital and one year at the other hospital. There were no unintentional tube removal events at these hospitals since Quickfix had been introduced.

In the nurse's descriptive questionnaire survey, 127 were enrolled (Table 1). The median working experience was 6 years (6 months-41 years). There was no significant difference between the two institutions (6 vs. 6 years, $\mathrm{P}=0.82)$. Except for 17 nurses with less than one year experience, all 110 nurses have performed handmade tape fixation. Seventy-two $(65.5 \%)$ of 110 learned the technique from colleagues, 22 (20.0\%) from doctors, 9 (8.2\%) from textbooks, and 7 (6.4\%) at workshops. The fixation method was standardized in the team [35 nurses $(31.8 \%)$ ], in the ward [20 nurses $(18.2 \%)$ ], while the method depended on the attending doctors [12 nurses (10.9\%)], and the fixation method varied according to the patients [43 nurses (39.1\%)]. With respect to the number of tape sheets used for handmade tape fixation, 64 nurses (58.2\%) used two sheets, $38(34.5 \%)$ used three sheets, and 8 (7.3\%) used four sheets. The $\Omega$-shaped tape was used in $110(100 \%)$ cases; round-cut, 108 (98.2\%) cases; and Y-shape slit 93 $(84.5 \%)$ cases.

The NPS for all nurses showed no significant difference between handmade tape fixation and Quickfix $\{5$ [5-8] vs. 5 [5-7] points, $\mathrm{P}=0.72$; Table 2\}. However, the NPS for handmade tape fixation for personnel with longer working experiences ( $>6$ years) was significantly better than that for personnel with shorter working experience $\{\geq 6$ years; 6 [5-8] vs. 5 [4-6] points, $\mathrm{P}=0.017$, correlation coefficient $\mathrm{r}=0.25, \mathrm{P}=0.012$; Table 3\}. On the other hand, the NPS for Quickfix based on the working experiences showed no

Table 2 Net promotor score of tape fixations in each occupation

\begin{tabular}{lccc}
\hline Occupation & Quickfix & Handmade tape fixation & P value \\
\hline Doctor & $10[5-10]$ & $7[5-8]$ & 0.34 \\
Nurse & $5[5-8]$ & $6[5-7]$ & 0.72 \\
\hline
\end{tabular}

Table 3 Net promotor score of tape fixation in working experiences

\begin{tabular}{lccc}
\hline Working experience duration (years) & $<6$ & $>6$ & $P$ value \\
\hline Handmade tape fixation & $5[4-6]$ & $6[5-8]$ & 0.017 \\
Quickfix & $5[4-8]$ & $5[2-8]$ & 0.88 \\
\hline
\end{tabular}


Table 4 Net promotor score of tape fixation in institutions

\begin{tabular}{lccc}
\hline Variable & Hospital A (use durations; 3 years 9 months) & Hospital B (use durations; 1 year) & P value \\
\hline Working experience duration (years) & $6[0.5-41]$ & $6[1-37]$ & 0.82 \\
NPS of Quickfix & $9[2-10]$ & $5[5-7]$ & $<0.001$ \\
\hline
\end{tabular}
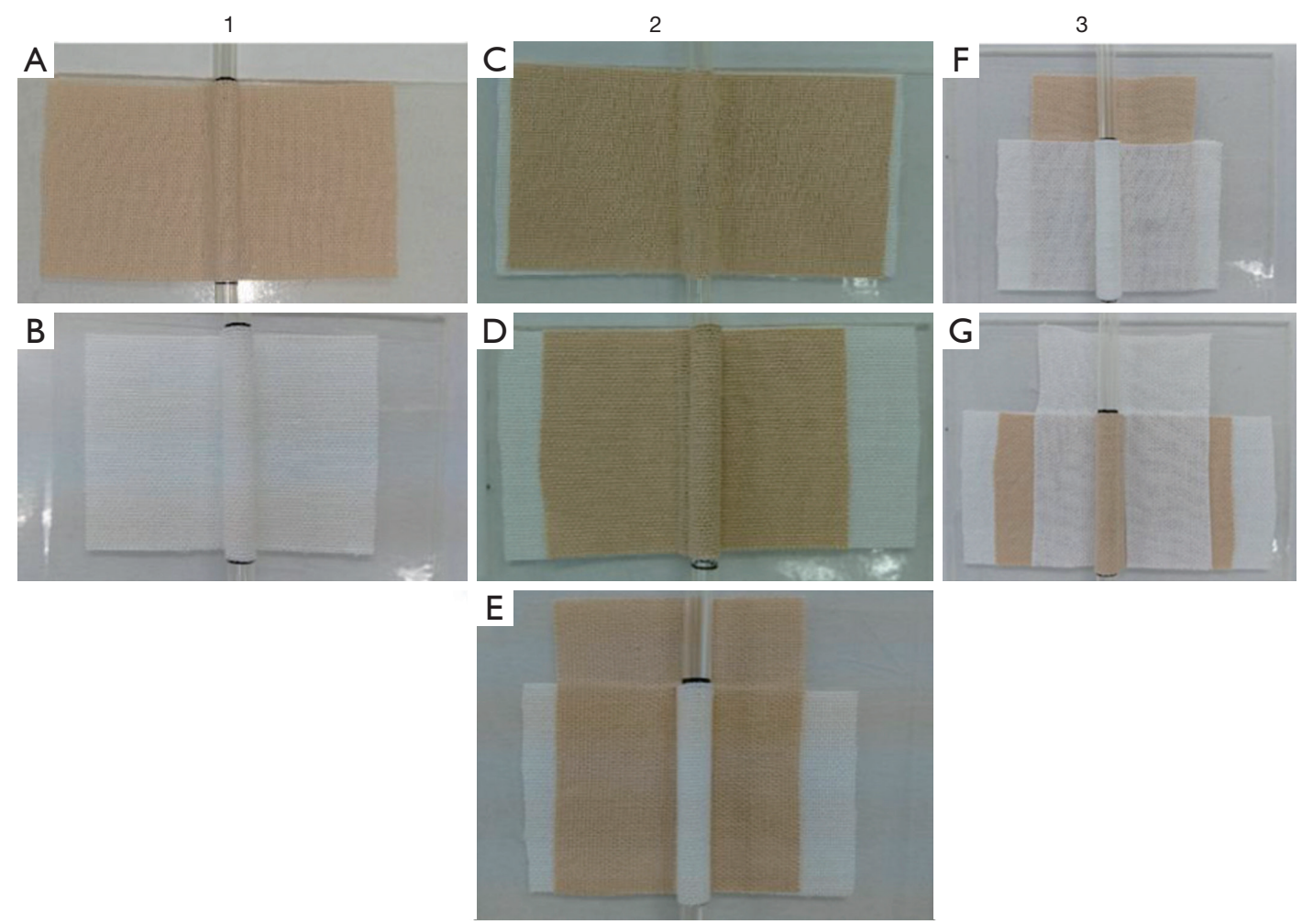

Figure 6 Various handmade tape fixations. (A) one sheet stick without $\Omega$-shape (type A); (B) one sheet stick with $\Omega$-shape (type B); (C) two sheets stick with foundation tape + type A (type C); (D) two sheets stick with foundation tape + type B (type D); (E) two sheets stick with foundation tape plus Y-shape slit (type E); (F) three sheets stick with type E + type B (type F); (G) three sheets stick with type D + Y-shape slit (type G).

differences between the groups $\{5[4-8]$ vs. 5 [2-8] points, $\mathrm{P}=0.88$, correlation coefficient $\mathrm{r}=0.13(\mathrm{P}=0.24)\}$. The NPS for Quickfix use in the hospital where it was used for a longer duration (3 years and 9 months) was significantly better than that for the hospital where it was used for a shorter duration $\{1$ years 0 months; 9 [2-10] vs. 5 [5-7] points, $\mathrm{P}<0.001$; Table 4\}.

\section{Tape fixation method}

Standardized methods of handmade tape fixation were as follows: one sheet stick without $\Omega$-shape (type A, Figure $6 A$ ), one sheet stick with $\Omega$-shape (type B, Figure $6 B$ ), two sheets stick with foundation tape + type A (type C, Figure 6C), two sheets stick with foundation tape + type B (type D, Figure 6D), two sheets stick with foundation tape plus Y-shape slit (type E, Figure $6 E$ ), three sheets stick with type $\mathrm{E}+$ type B (type F, Figure $6 F)$, three sheets stick with type D + Y-shape slit (type G, Figure $6 G$ ). The frequency of fixation type was the following: type D had the most handmade fixation (40.0\%), type E; $18.2 \%$, type F; $16.4 \%$, type G; $10.0 \%$, and all other methods were less than $10 \%$. 


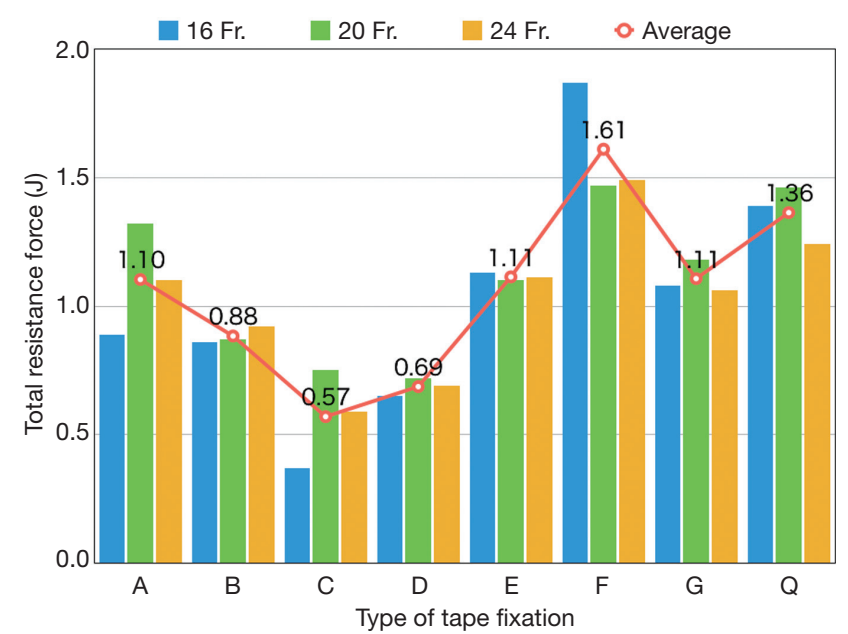

Figure 7 Average values of total resistance force [Joule (J)] under each tube size condition. The data showed that the resistance was the highest for type F followed by Quickfix.

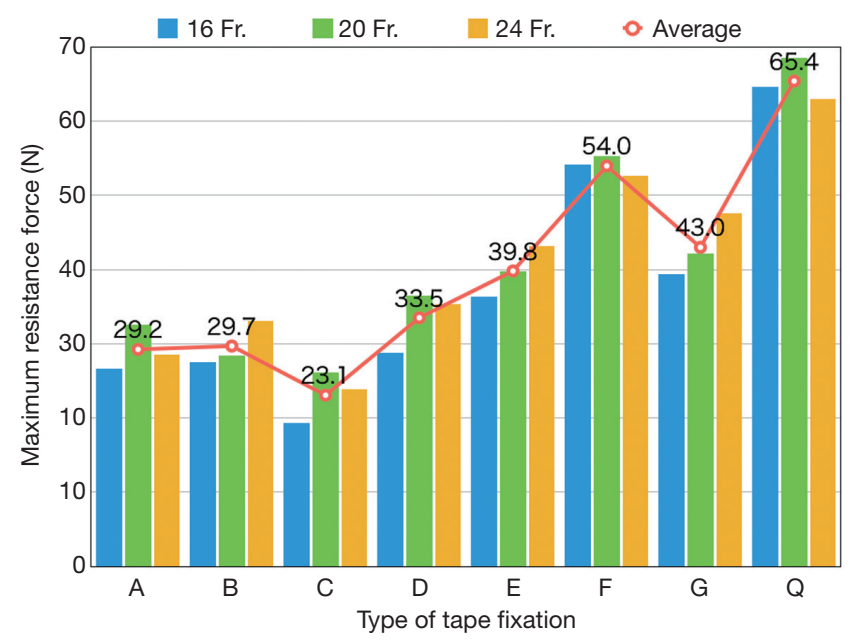

Figure 8 Average values of maximum resistance force [Newton (N)] under each tube size condition. The data showed that the resistance of Quickfix was the highest followed by type F.

\section{Tape fixing strength comparison test}

The average values of fixing strength under each tube size conditions were as follows (Figures 7,8): type A was 1.10 (0.89-1.32) J and $29.2(26.6-32.6) \mathrm{N}$; type B, $0.88(0.86-$ $0.92) \mathrm{J}$ and $29.7(27.6-33.1) \mathrm{N}$; type C, $0.57(0.37-0.75) \mathrm{J}$ and $23.1(19.3-23.9) \mathrm{N}$; type $\mathrm{D}, 0.69(0.65-0.72) \mathrm{J}$ and 33.5 (28.8-36.5) N; type E, $1.11(1.10-1.13) \mathrm{J}$ and 39.8 (36.443.2) $\mathrm{N}$; type F, $1.61(1.47-1.87) \mathrm{J}$ and $54.0(52.6-55.2)$ $\mathrm{N}$; type $\mathrm{G}, 1.11(1.06-1.18) \mathrm{J}$ and $43.0(39.3-47.5) \mathrm{N}$; and

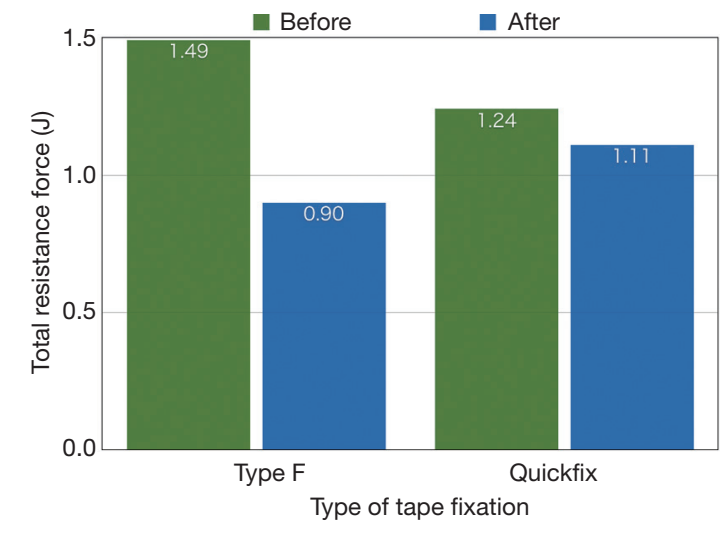

Figure 9 Total resistance force [Joule (J)] under skin coating agent using a 24-Fr tube. The decrease was greater for type $\mathrm{F}$ than for Quickfix.

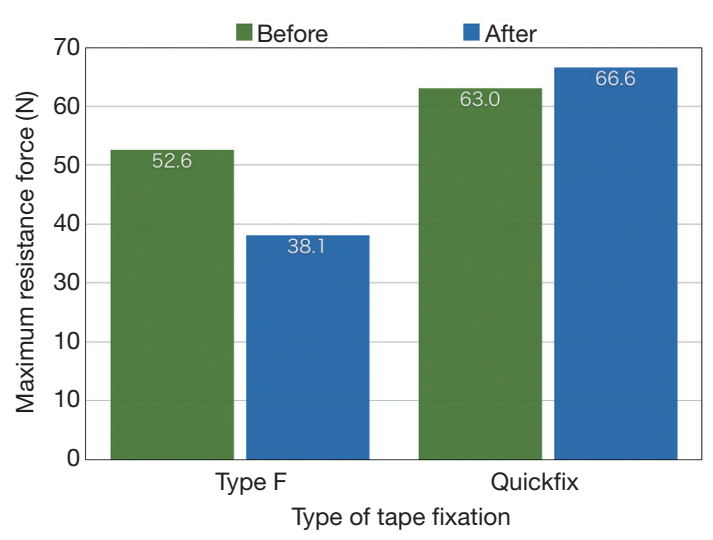

Figure 10 Maximum resistance force [Newton (N)] under skin coating agent under skin coating agent using a 24-Fr tube. Quickfix did not show an obvious change, although the maximum resistance force type F decreased.

Quickfix, $1.36(1.24-1.46) \mathrm{J}$ and $65.4(63.0-68.5) \mathrm{N}$.

In the fixing strength under the skin coating material, type F and Quickfix had the highest resistance. The values of type $\mathrm{F}$ with skin coating agent decreased from 1.49 to $0.90 \mathrm{~J}$ and 52.6 to $38.1 \mathrm{~N}$. In contrast, the values of Quickfix did not show an apparent change from 1.24 to $1.11 \mathrm{~J}$ and 63.0 to $66.6 \mathrm{~N}$ (Figures 9,10 ).

\section{Discussion}

Patients expect safe, secure, and high-quality medical care, which is focused on preventing and minimizing any complication. To achieve these goals, it is necessary to 
Table 5 Summary of tape fixation

\begin{tabular}{lcc}
\hline Variable & Handmade fixation & Quickfix \\
\hline Institution variation & Yes & No \\
Individual variation & Yes & No \\
Empirical cut techniques & Variable & Including \\
NPS & Lower in shorter experience worker & Higher regardless of experience or occupation \\
\hline
\end{tabular}

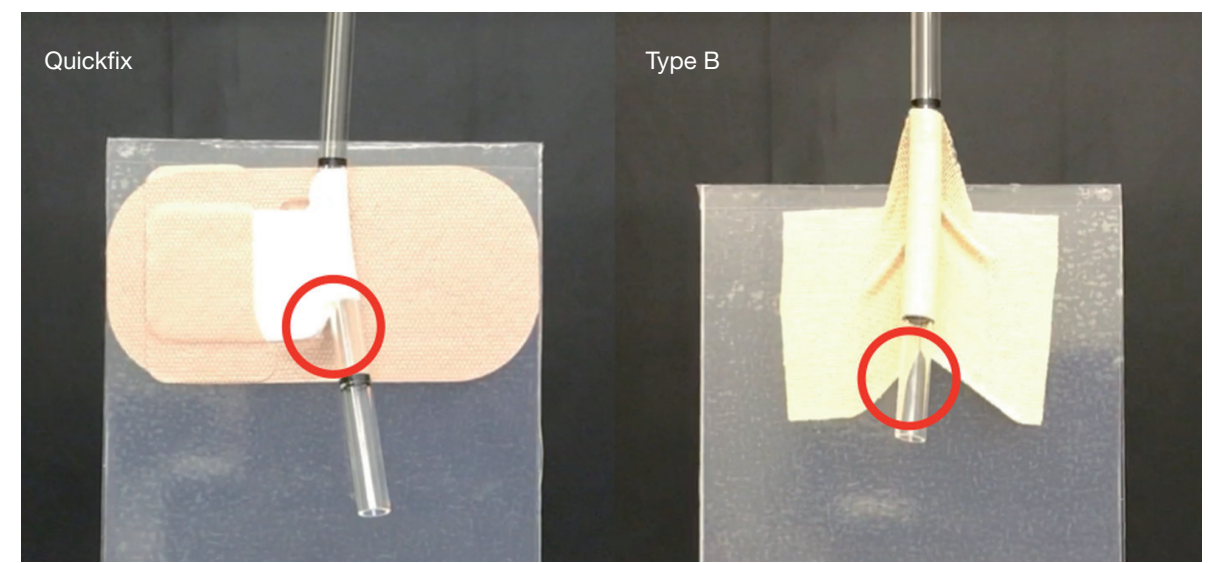

Figure 11 Red circle showing the first peeling off portions. These were noted the side closest to the chest tube.

standardize medical care without inefficiency and variability, and the standardization will result in a contribution to highquality, safety and medical resource savings.

Chest tube management was reported to be affected by the quality of care provided by the residents or nurses $(3,4)$. Chest tube fixation was generally reinforced with tape in Japan, but the exact method depends on facilities, departments, or staff. It has also been affecting the patient's skin, physical, and medical condition. Handmade tape fixations were based on individual experiences and did not have consistency or any evidence. Our NPS data showed that handmade tape fixations were affected by the duration of work experience. Younger nurses tended to not have learned tape fixation, although the method was taught by older colleagues.

On the other hand, Quickfix fixation showed equal or better NPS data when compared to conventional homemade tape fixations, regardless of working durations. Quickfix is a product that can incorporate fixation using empirical techniques, such as application of round-cut (Figure $3 A$ ) and $\Omega$-shape tape (Figure $3 D$ ). Round-cuts reduce the friction forces at the tape edges, prevent peel off, and decrease skin troubles. Although most nurses performed these techniques, doctors varied widely (nurses $98.2 \%$ vs. doctors 14.3\%) (Table 1). Quickfix can be applied by experienced and inexperienced staff, and Quickfix was thought to be a product realizing medical standardization (Table 5).

In the safety management of tubes, the important thing is not only standardization but also a secure fixation. The as fixation tape increases in strength, the more skin trouble could occur (Figure 4). Techniques such as round-cut and $\Omega$-shape stick (Figure $3 A, D$ ) and skin coating agents such as Remois Coat (ALCARE, Tokyo, Japan) or Secura (Smith and Nephew, Watford, UK) are some of methods that maximize adhesive strength and minimize skin trouble. However, we concerned whether tape-fixation keeps its strength under skin coating materials, compared with not applied for it. Our data showed that Quickfix could maintain fixing strength even under application, while handmade fixation decreased the strength. In any tape fixation, the first peeling off portions was the close side of chest tube (Figure 11). We guessed that Quickfix maintained fixing force because the portion was structurally unaffected by the coating material.

Fixation products can provide the same method without unnecessary processes. There are some differences between 
time-cost and economic-cost between products. Quickfix can provide the fixation in about 30 seconds. SecurAcath and StatLock were reported to require 4.3 to 7.3 minutes (6). Quickfix was made of paper tape, need not have significant storage space, and inexpensive (40-60 yen). Other fixation products were made of plastic and more expensive. However, differences in fixation strength force were unknown.

\section{Limitations}

There are several limitations of this study. The study was restricted in terms of the use of chest tube, tape material, number of cases assessed, and fixation strength tests wherein the tape was pulled vertically. When the tube was removed unintentionally, we could not ensure whether the tape was pulled out in any directions. Basically, tape fixation of the chest tubes may be a practice restricted to Japan.

This multi-center questionnaire survey revealed that many tape fixation methods are used. Quickfix fixation showed equal or better NPS data compared to the conventional handmade tape fixation, regardless of the level of work experience. Besides, Quickfix allowed secure tape fixation even when a skin coating was applied. Therefore, Quickfix was supposed to be the best tape fixation agent and may contribute to standardization of the fixation procedure.

\section{Conclusions}

Several tape fixations methods of chest tube have been used, despite the lack of a scientific basis. This study revealed that Quickfix showed secure fixation, regardless of tube size or skin coating. Quickfix could be considered the best and standardized fixation because not only stronger but safe, simple, inexpensive, reliable, carrying out equally by anyone.

\section{Acknowledgments}

We thank the doctors for collecting data at the following institutions: University of Toyama, Joetsu General Hospital, University of Kanazawa, Kanazawa Medical University, Niigata Prefectural Central Hospital, Ishikawa Prefectural Central Hospital, Toyama Prefectural Central Hospital, Fukui Prefectural Hospital, University of Fukui, Toyama Red Cross Hospital, Kouseiren Takaoka Hospital, Komatsu Municipal Hospital, Fukui-ken Saiseikai Hospital, National Hospital Organization Kanazawa Medical Center, and Itoigawa General Hospital. We also thank the nurses for collecting data at the following institutions: University of Toyama, Joetsu General Hospital.

Funding: None.

\section{Footnote}

Conflicts of Interest: The authors have no conflicts of interest to declare.

Ethical Statement: The authors are accountable for all aspects of the work in ensuring that questions related to the accuracy or integrity of any part of the work are appropriately investigated and resolved. The study was approved by the Ethics Committee of the Joetsu General Hospital (J181).

Open Access Statement: This is an Open Access article distributed in accordance with the Creative Commons Attribution-NonCommercial-NoDerivs 4.0 International License (CC BY-NC-ND 4.0), which permits the noncommercial replication and distribution of the article with the strict proviso that no changes or edits are made and the original work is properly cited (including links to both the formal publication through the relevant DOI and the license). See: https://creativecommons.org/licenses/by-nc-nd/4.0/.

\section{References}

1. Bryant AS, Cerfolio RJ. Chest tube management. In: Kuzdzaf J. editor. ESTS textbook of thoracic surgery. Volume 1. Krakow: Medycyna Praktyczna, 2014:75.

2. Mentzer SJ. Postoperative management. In: Sugarbaker DJ. editor. Adult chest surgery. New York: McGraw-Hill, 2009:78.

3. Ruparel RK, Laack TA, Brahmbhatt RD, et al. Securing a chest tube properly: a simple framework for teaching emergency medicine residents and assessing their technical abilities. J Emerg Med 2017;53:110-5.

4. Marsh N, Webster J, Mihala G, et al. Devices and dressing to secure peripheral venous catheters to prevent complication. Cochrane Database Syst Rev 2015;12:CD011070.

5. Buckley JC, Brown AP, Shin JS, et al. A comparison of the Haider Tube-Guard endotracheal tube holder versus adhesive tape to determine if this novel device can reduce endotracheal tube movement and prevent unplanned extubation. Anesth Analg 2016;122:1439-43. 
6. Goossens GA, Grumiaux N, Janssens C, et al. SecureAstaP trial: securement with SecurAcath versus StatLock for peripherally inserted central catheters, a randomized open trial. BMJ Open 2018;8:e016058.

7. Hampson J, Green C, Stewart J, et al. Impact of the introduction of an endotracheal tube attachment device on the incidence and severity of oral pressure injuries in the intensive care unit: a retrospective observational study. BMC Nurs 2018;17:4.

Cite this article as: Homma T, Ojima T, Shimada Y, Akemoto Y, Yoshimura N. Use of Quickfix for tape fixation of chest tubes: a multi-center doctor-nurse questionnaire survey and fixing strength comparison study. J Thorac Dis 2020;12(3):493-503. doi: 10.21037/jtd.2019.12.132
8. Cook M, Idzior L, Albert NM. Nurse and patient factors that influence nursing time in chest tube management early after open heart surgery: a descriptive, correlational study. Intensive Crit Care Nurs 2017;42:116-21.

9. Meyer T, Funke A, Munch C, et al. Real world experience of patients with amyotrophic lateral sclerosis (ALS) in the treatment of spasticity using tetrahydrocannabinol: cannabidiol (THC: CBD) BMC Neurol 2019;19:222. 